\title{
Complication avoidance in laser interstitial thermal therapy: lessons learned
}

\author{
Rachel Pruitt, BS, ${ }^{1}$ Alexander Gamble, DO, ${ }^{2}$ Karen Black, MD, ${ }^{1,3}$ Michael Schulder, MD, ${ }^{1,2}$ and \\ Ashesh D. Mehta, MD, PhD ${ }^{1,2}$ \\ ${ }^{1}$ Hofstra Northwell School of Medicine, Hempstead; and Departments of ${ }^{2}$ Neurosurgery and ${ }^{3}$ Radiology, North Shore University \\ Hospital, Manhasset, New York
}

\begin{abstract}
OBJECTIVE Complications of laser interstitial thermal therapy (LITT) are underreported. The authors discuss how they
\end{abstract} have modified their technique in the context of technical and treatment-related adverse events.

METHODS The Medtronic Visualase system was used in 49 procedures in 46 patients. Between 1 and 3 cooling catheters/laser fiber assemblies were placed, for a total of 62 implanted devices. Devices were placed using frameless stereotaxy $(n=3)$, frameless stereotaxy with intraoperative MRI (iMRI) $(n=9)$, MRI under direct vision $(n=2), M R I$ alone $(n=1)$, or frame-based $(n=47)$ techniques. LITT was performed while monitoring MRI thermometry. Indications included brain tumors $(n=12)$, radiation necrosis $(n=2)$, filum terminale ependymoma $(n=1)$, mesial temporal lobe epilepsy $(n=$ $21)$, corpus callosotomy for bifrontal epilepsy $(n=3)$, cavernoma $(n=1)$, and hypothalamic hamartomas $(n=6)$.

RESULTS Some form of adverse event occurred in $11(22.4 \%)$ of 49 procedures. These included 4 catheter malpositions, 3 intracranial hemorrhages, 3 cases of neurological deficit related to thermal injury, and 1 technical malfunction resulting in an aborted procedure. Of these, direct thermal injury was the only cause of prolonged neurological morbidity and occurred in 3 of 49 procedures. Use of frameless stereotaxy and increased numbers of devices were associated with significantly increased complication rates $(p<0.05)$. A number of procedural modifications were made to avoid complications, including the use of 1) frame-based catheter placement, a 1.8-mm alignment rod to create a track and titanium skull anchors for long trajectories to improve accuracy; 2) a narrow-gauge instrument for dural puncture and coregistration of contrast MRI with CT angiography to reduce intracranial hemorrhage; 3) general endotracheal anesthesia for posterior-placed skull anchors to reduce the likelihood of damage to the cooling catheter; 4) use of as few probes as possible to reduce complications overall; and 5) dose modification of thermal treatment and use of short (3-mm) diffusing tips to limit treatment when structures to be spared do not have intervening CSF spaces to act as heat sinks.

CONCLUSIONS Laser ablation treatment may be used for a variety of neurosurgical procedures for patients with tumors and epilepsy. While catheter placement and thermal treatment may be associated with a range of suboptimal operative and postoperative courses, permanent neurological morbidity is less common. The authors' institutional experience illustrates a number of measures that may be taken to improve outcomes using this important new tool in the neurosurgical arsenal.

https://thejns.org/doi/abs/10.3171/2016.3.JNS152147

KEY WORDS laser interstitial thermal therapy; LITT; minimally invasive neurosurgery; surgical technique

$\mathrm{H}$ YPERTHERMIA as a tool in operative neurosurgery has a history going back several decades. ${ }^{21,36}$ Lack of precision and uncertainty regarding the volumes and actual temperatures delivered has prevented this method from being widely accepted. Laser interstitial thermal therapy (LITT), first proposed in the $1980 \mathrm{~s},{ }^{1}$ has generated excitement recently in the neurosurgical community. It has been proposed as an ablative tool for patients with lesions when minimal invasiveness is desired.
LITT uses MRI-compatible fibers that transmit laser energy and are inserted into stereotactically placed cooling catheters to deliver targeted hyperthermia. Multiple studies have shown promising results in the use of LITT for the treatment of patients with radiation necrosis, ${ }^{5,30,32}$ drugrefractory epilepsy, ${ }^{10,11,45,48}$ hypothalamic hamartomas, ${ }^{45,47}$ and primary $2,15,16,18,22,27,28,38,41,42$ and metastatic ${ }^{3,4,15,44}$ brain tumors. In addition, while $\mathrm{CO}_{2}$ laser systems have been described for patients needing corpus callosotomy, ${ }^{7,13}$ for

ABBREVIATIONS CTA = CT angiography; HIFU = high-intensity focused ultrasound; iMRI = intraoperative MRI; LITT = laser interstitial thermal therapy; PAD = precision aiming device; SRS = stereotactic radiosurgery.

SUBMITTED September 13, 2015. ACCEPTED March 24, 2016.

INCLUDE WHEN CITING Published online June 3, 2016; DOI: 10.3171/2016.3.JNS152147. 
intractable epilepsy as well as cavernomas, ${ }^{6.9}$ we describe our experience using the Nd-YAG Visualase LITT system (Medtronic).

In general, the potential advantages of LITT include a minimally invasive approach, decreased length of hospital stay relative to higher risk open procedures, and patient preference. LITT also presents an alternative therapy for tumor patients who have already been treated with radiation therapy, and/or whose tumor location is unfavorable for open resection. While the advantages of LITT have been well documented, the complications associated with this technology are seemingly underreported and have never been investigated in a series of this size. In this paper, we examine our experience with LITT, associated adverse events, and the lessons learned.

\section{Methods \\ Patient Selection}

Patients with brain tumors were considered for LITT for recurrence after prior surgery and/or radiation therapy or stereotactic radiosurgery (SRS). Patients with medically refractory epilepsy were offered LITT if they had medial temporal sclerosis with concordant electroencephalography data $(\mathrm{n}=16)$, lesions within the medial temporal lobe $(\mathrm{n}=2)$, or invasive monitoring revealing medial temporal onset $(n=3)$. The patients were offered open surgical treatment with selective amygdalohippocampectomy, which is an effective method with a proven track record over decades, versus LITT to the hippocampus, a novel minimally invasive treatment with good early results. Patients were also offered LITT if they had medically refractory epilepsy requiring a callosotomy $(\mathrm{n}=3)$, a cavernoma $(n=1)$, or a hypothalamic hamartoma $(n=6)$. In all cases, LITT was performed based on patient preference.

A total of 46 patients underwent 49 LITT procedures at our institution with a total of 62 catheter/laser fiber assemblies placed between 2009 and 2015. This includes 13 patients with CNS tumors, 2 patients with radiation necrosis, and 31 patients with epilepsy.

\section{Visualase System}

The Visualase system was used for all patients undergoing LITT procedures. This consists of a disposable catheter that is implanted and accommodates a fiber that can transmit laser energy. In our series, both the catheter and laser fiber were placed in the operating room under sterile conditions. The patient was then brought to the MRI suite, where a $980-\mathrm{nm}$ diode laser generator that is adjustable to $15 \mathrm{~W}$, saline pump, and workstation were attached to the cooling catheter/laser fiber assembly via extension lines that entered the shielded room housing the magnet. The tip of the fiber consists of a translucent diffuser that is either 3 or $10 \mathrm{~mm}$ in length and transmits light energy along that length.

\section{Surgical Technique}

Each patient underwent preoperative T1-weighted MRI with contrast (Magnevist, Bayer Healthcare) prior to the procedure. When used, a stereotactic head frame was placed on the day of surgery, and either noncontrast or contrast-enhanced 0.625 -mm-cut axial CT scanning was performed. This MRI study was then fused with the stereotactic CT or intraoperative MRI (iMRI) for trajectory mapping (StealthStation, Medtronic; or Radionics, Integra). An automated fusion was performed, and its accuracy was assessed by the correspondence of vascular landmarks. If this correspondence showed greater than 1.5 $\mathrm{mm}$ of disparity with regard to vascular structures, linear fusion was performed by selecting 10 specific vascular landmarks (e.g., internal carotid artery bifurcation and termination of the basilar artery) on contrast-enhanced CT and MRI. iMRI was performed using the 0.15-T Polestar system (Medtronic).

For the procedure, the patient was placed either under conscious sedation (11 procedures) or general anesthesia (38 procedures). A stab incision was made, followed by a 3.2-mm twist-drill hole. Navigation was performed using frameless stereotaxy alone (in 2 patients, 3 devices), frameless stereotaxy with iMRI (in 5 patients, 9 devices), a stereotactic frame (in 37 patients, 47 devices), MRI guidance (in 1 patient, 1 device), and iMRI alone (in 1 patient, 2 devices). Frameless stereotaxy was used in conjunction with a precision aiming device (PAD). The PAD allows for adjustment along any 2 orthogonal planes of rotation that can be rigidly attached to an adjustable articulated arm affixed to the patient via the Mayfield headholder. This device can accommodate a stereotactic pointer to align the actual trajectory to one planned on the Medtronic StealthStation. The device was secured using a Visualase plastic bone anchor (45 devices), a metal bone anchor (PMT Corp.) (10 devices), the Stealth Navigus (4 devices), or with a silk suture (3 devices). In 33 procedures (41 devices), an alignment rod was first passed through the stereotactic apparatus, over which the bone anchor was secured. The alignment rod is a $20-\mathrm{cm}$-long, 14-gauge rigid stainless steel device that has a dual purpose. Analogous to a guidewire, it can be placed into a reducing tube in the frame to maintain the alignment of the trajectory when the skull anchor is placed. It can also be used to create a track within the brain parenchyma for the subsequent placement of the slightly more flexible cooling catheter. The catheter was then introduced through the bone anchor and passed to the appropriate length to reach the target under fluoroscopic guidance. Finally, the laser fiber was placed within the cooling catheter in the operating room. Laser fibers were equipped with 2 types of diffusing tips, either $3 \mathrm{~mm}$ (for all hypothalamic hamartoma cases) or $10 \mathrm{~mm}$ (for the remaining cases). If used, the stereotactic frame was removed in the operating room prior to MRI.

In the MRI suite, a receiving/transmitting coil was used for all cases except when stereoelectroencephalography depth electrodes were in place, in which case a receivingonly coil was used. T1-weighted MRI was performed to evaluate for hemorrhage, which was evident at this time in 2 of the 3 cases when this occurred. In each patient, the small hemorrhage identified enabled us to proceed with treatment while performing imaging. LITT was performed with thermometry obtained every 10 seconds on an anatomically oblique image. Temperature boundaries (typically $50^{\circ} \mathrm{C}$ over areas to be spared and $90^{\circ} \mathrm{C}$ at the lesion center) were programmed to limit hyperthermia. 
A test dose of approximately $3 \mathrm{~W}$ was administered for 10-20 seconds. Once localization of the probe was confirmed, the ablation was performed and monitored with thermometry for the length of time deemed appropriate by the surgeon (1-3 minutes). Maximal energy delivered was kept below $5 \mathrm{~W}$ for the hypothalamic hamartoma cases, $7.5 \mathrm{~W}$ for callosotomy, and $12 \mathrm{~W}$ for the remaining cases. The LITT software generates an estimate of tissue damage in near-real time, using the Arrhenius model that uses temperature plus time to calculate the "kill zone." If additional treatment was indicated, the fiber was manually retracted within the catheter 1-4 times as needed in the MRI suite, and a test dose was repeated to assess the location of the tip using MR thermometry. Occasionally, the entire assembly was advanced when the target of treatment was beyond the area of treatment. When the desired volume was fully treated, the implanted device was usually removed in the MRI suite, and the incision site was closed with a staple. Patients who underwent the procedure with the use of the Navigus system (4 procedures) were transferred back to the operating room where it was removed.

\section{Literature Review}

A literature review was conducted using PubMed. The search used the terms laser interstitial thermal therapy and brain. Results were limited to clinical reports written in the English language. This search yielded 7 results, of which 2 were excluded, one due to using LITT for oropharyngeal cancers rather than purely CNS lesions, and the other because it was a case report of a patient likely included in a larger series by the same author. ${ }^{3,4,12,32,42}$ In addition, the most recent reviews on the topic were reviewed, ${ }^{16,29,31}$ and all clinical studies cited (those that did not appear in the original search) were included.

\section{Results}

Procedural complications can result from suboptimal catheter placement, resulting in hemorrhage or subsequent inability to adequately complete the planned treatment because of the LITT hyperthermia itself, or because of technical complications of the catheter cooling system. Accordingly, $11(22.4 \%)$ of 49 procedures were suboptimal in some fashion. Details are illustrated in Tables 1 and 2.

\section{Device Malposition}

Four patients (Cases 6, 9, 33, and 40) had suboptimal catheter positioning. Factors that may have been associated with this included use of the PAD (Fig. 1, Case 6), not using an alignment rod (Case 9), use of frameless stereotaxy (Case 33), and use of multiple devices (Case 40). We adapted our technique accordingly to rely on frame-based stereotaxy, use an alignment rod, and place as few devices as possible. We often noted a small angular displacement of plastic skull anchors after inserting them prior to placement of the laser device and believe that this might have been the source of a number of cases in which there was device malposition. We abandoned these plastic skull anchors for titanium devices after our 40th patient and have not had a malpositioned device since.

\section{Hemorrhage}

Catheter placement resulted in hemorrhage in 2 patients (Cases 18 and 38); in one additional case (Case 17), hemorrhage was likely secondary to catheter removal. In Case 17, we believe that use of general anesthesia might have avoided this complication. The patient had an occipitally placed plastic skull anchor, which was damaged when she moved her head while undergoing MRI during the last of 3 ablations. This resulted in damage to the cooling system as the catheter was kinked, leading to overheating and charring of the tissue. It is likely that the charred tissue in the region of the choroid was adherent to the catheter surface and avulsed leading to hemorrhage when the device was removed. Consistent with this hypothesis, the final T2-weighted FLAIR and T1-weighted MRI scans showed normal results, and intraventricular hemorrhage was only evident on routine $\mathrm{CT}$ the following morning.

In another case (Case 38), epidural hematoma was secondary to inadequate dural puncture, thereby stripping dura from the periosteum (Fig. 2). In a third case of hemorrhage (Case 18), intraparenchymal hemorrhage was likely secondary to vascular injury during device insertion. We should note that in both of these cases, it was possible to complete the LITT treatment despite the hemorrhage evident on the initial scan. In both cases, the hemorrhages produced only local mass effect, and the size could be monitored during the 1-hour period required to complete the treatment. The patient in Case 18 was managed conservatively, while the patient in Case 38 required a craniotomy for evacuation of the epidural hematoma. Of note, in all cases of hemorrhage, multiple devices were used. To limit these types of events, we have adopted measures to reduce device malfunction, parsimony of devices, CT angiography (CTA) fusion to MRI, and use of a needle to open the dura.

\section{LITT Hyperthermia}

Three patients had complications associated with the LITT hyperthermia itself (Case 8,21, and 22). Case 8 underwent LITT for a recurrent filum terminale ependymoma. This treatment resulted in paraplegia and incontinence that was evident on postoperative Day 1 . Case 21 underwent LITT to a previously radiated right frontal lung metastasis, resulting in worsened edema and a new hemiparesis that partially resolved. Case 22 underwent LITT for recurrent vermian glioblastoma and developed new bilateral cranial nerve VI and VII palsies. As a result of these 3 events, we have applied increased caution when using LITT in situations in which the LITT target and structures to be spared are not marked by CSF spaces that provide heat sinks that limit thermal injury. We also used this experience to use smaller (3-mm) diffusing tips in patients in whom targets of ablation were contiguous with normal tissue that should be spared, including all cases of $\mathrm{HH}$.

\section{Technical Malfunction}

Two cases of technical malfunction occurred. One patient (Case 17) for whom this likely resulted in an asymptomatic intraventricular hemorrhage is described above. In Case 37, the saline irrigation solution was filled inad- 
TABLE 1. Complications

\begin{tabular}{|c|c|c|c|c|c|c|c|}
\hline $\begin{array}{l}\text { Case } \\
\text { No. }\end{array}$ & $\begin{array}{l}\text { Age (yrs), } \\
\text { Sex }\end{array}$ & Pathology & Location & Frame & Anesthesia & $\begin{array}{l}\text { No. of } \\
\text { Devices }\end{array}$ & Complication \\
\hline 6 & $56, F$ & Lung & Right parietal & PAD, iMRI & GETA & 2 & Malposition \\
\hline 8 & $72, \mathrm{~F}$ & $\begin{array}{l}\text { Spinal myxopapillary } \\
\text { ependymoma }\end{array}$ & Cauda equina & MRI guidance & Sedation & 1 & Hyperthermia, cauda equina \\
\hline 9 & $32, \mathrm{M}$ & Rt MTLE & Lt medial temporal lobe & Leksell & Sedation & 1 & Malposition \\
\hline 17 & $40, \mathrm{~F}$ & Rt MTLE & Rt medial temporal lobe & CRW & Sedation & 2 & $\begin{array}{l}\text { Device malfunction, intraventricu- } \\
\text { lar hemorrhage }\end{array}$ \\
\hline 18 & $60, \mathrm{~F}$ & Rt MTLE & Rt medial temporal lobe & CRW & GETA & 2 & Intraparenchymal hematoma \\
\hline 21 & $64, \mathrm{~F}$ & Lung & Right frontal & CRW & GETA & 1 & Hyperthermia, It hemiparesis \\
\hline 22 & $29, \mathrm{M}$ & GBM & Cerebellar and periventricular & CRW & GETA & 1 & Hyperthermia CN VI \& VII 7 palsy \\
\hline 33 & $61, \mathrm{M}$ & $\begin{array}{l}\text { Lung, radiation } \\
\text { necrosis }\end{array}$ & $\begin{array}{l}\text { Rt splenium of the corpus } \\
\text { callosum }\end{array}$ & PAD & GETA & 2 & Malposition \\
\hline 37 & $71, \mathrm{M}$ & GBM & Rt thalamus & CRW & GETA & 1 & Cooling malfunction \\
\hline 38 & $24, \mathrm{M}$ & $\mathrm{HH}$ & Hypothalamus & CRW & GETA & 2 & Epidural hematoma \\
\hline 40 & $29, \mathrm{~F}$ & Bifrontal epilepsy & Corpus callosum & CRW & GETA & 3 & Malposition \\
\hline
\end{tabular}

$\mathrm{CN}=$ cranial nerve; $\mathrm{CRW}=$ Cosman-Roberts-Wells; DNET = dysembryoplastic neuroepithelial tumor; GBM = glioblastoma; GETA = general endotracheal anesthesia; $\mathrm{HH}=$ hypothalamic hamartoma; MTLE = mesial temporal lobe epilepsy.

equately, resulting in overheating at the laser tip and premature conclusion of the procedure. We paid increased attention to adequate filling of coolant and use of general anesthesia for posterior device placement as a result of this experience.

\section{Discussion}

While experience with LITT has been well reported, ${ }^{2-5}$, $10,11,15,16,18,22,27,28,30,32,38,42,44,45,47,48$ the complications and technical malfunctions resulting from LITT are less frequently discussed. In our relatively large experience, we identify 3 potential points where complications can arise: catheter placement, LITT hyperthermia, and technical malfunctions of the cooling system. Reported complications in the current literature on LITT treatment, including 25 clinical reports and treatment of 243 patients, are listed in Table 3. ${ }^{2-4,10-12,15,18,19,22,27,32-40,42-44,47,48}$

\section{Comparison With Prior Reports of Complications}

There have been 4 reported instances of catheter malposition. $3,18,48$ Reported complications from catheter placement include subdural hematoma $(\mathrm{n}=1),{ }^{48}$ hemorrhage from arterial injury $(n=1),{ }^{18}$ subarachnoid hemorrhage ( $n$

\section{TABLE 2. Complication rates}

\begin{tabular}{lcc}
\hline Complication & No. of Complications & \% Devices Placed \\
\hline Malposition & 4 & 6.5 \\
\hline Hemorrhage & 3 & 4.8 \\
\hline LITT treatment & 3 & 4.8 \\
\hline Technical & 2 & 3.2 \\
\hline Total & $11^{*}$ & 17.7 \\
\hline
\end{tabular}

* One patient (Case 17) had both technical complication and intraventricular hemorrhage resultant from the same laser fiber/catheter assembly.
$=1),{ }^{47}$ and one instance in which a gliosarcoma may have arisen secondary to seeding of neoplastic cells along the catheter track. ${ }^{42}$ Jethwa et al. reported an overall accuracy of $83.7 \%$ using the PAD with the Visualase skull anchor. ${ }^{18}$ Our experience indicates that use of frame-based techniques as well as metal skull anchoring devices provides superior accuracy of catheter placement. We do not have experience with positioning LITT catheters using stereotactic devices designed to be used in the MRI suite environment, but we acknowledge that these may potentially provide a high degree of accuracy.

There have been 3 reported cases of patients sustaining hemorrhage associated with LITT, including one subdural hematoma, ${ }^{48}$ one from arterial injury, ${ }^{18}$ and one subarachnoid hemorrhage ${ }^{47}(3 / 243,1.2 \%$ of patients reviewed). In comparison, we have had 3 patients experience a hemorrhage: 1 intraparenchymal, 1 intraventricular, and 1 epidural hematoma. Our retrospective analysis suggests that a number of modifications may be made to reduce the risk of hemorrhage. These include using a sharp instrument for dural puncture, CT angiography/MRI fusion that is verified with vascular landmarks, and taking care to avoid coolant malfunction.

Reported complications from LITT hyperthermia itself include new or worsening neurological deficits (dysphasia, ${ }^{3,15,32,33}$ paresis, ${ }^{15,22,38,42}$ homonymous hemianopia, ${ }^{11}$ seizure, ${ }^{2,27}$ cerebellar syndrome, ${ }^{3}$ short-term memory loss, ${ }^{10}$ and unspecified ${ }^{2,27}$ ), infection (brain abscess, ${ }^{22}$ wound infection, ${ }^{22,27}$ and ventriculitis ${ }^{27}$ ), diabetes insipidus, ${ }^{18}$ hyponatremia, ${ }^{15,27}$ pseudoaneurysm, ${ }^{42}$ blood suffusion, ${ }^{3}$ edema requiring hemicraniectomy, ${ }^{18}$ and CSF leak. ${ }^{2}$ As in our series, these previously reported adverse events rarely result in permanent neurological morbidity $(14 / 243,5.8 \%$ of patients reviewed). A comparison of our results with previous reports demonstrates a similar overall frequency of adverse events. However, our results demonstrated a somewhat higher frequency of permanent complications, 


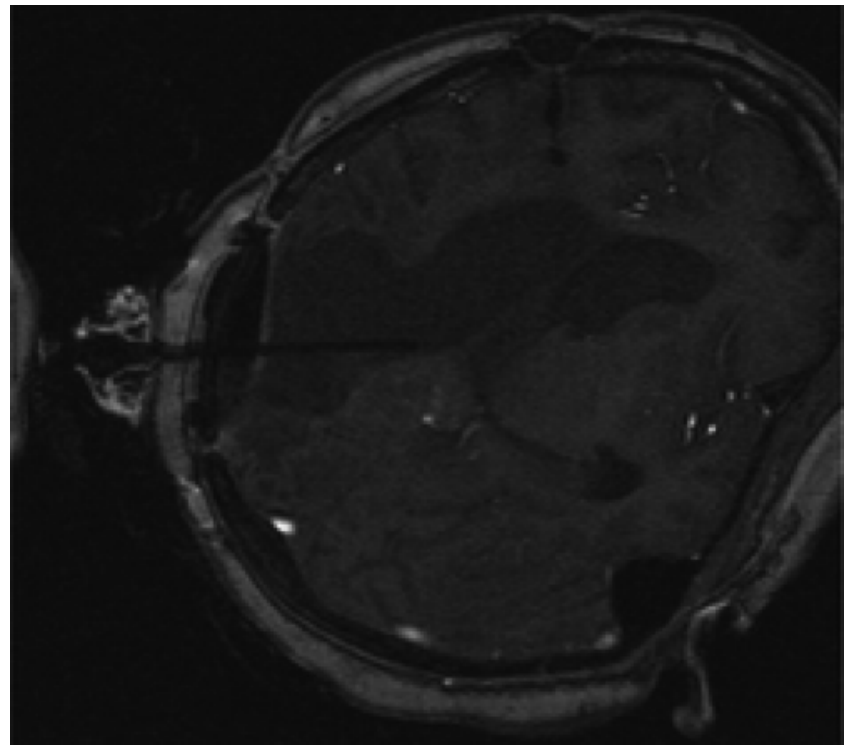

FIG. 1. Case 6. Axial T1-weighted MR image demonstrating probe misplacement adjacent to the parietal lesion.

as 3 of the 49 procedures $(6.1 \%)$ resulted in some type of permanent neurological deficit, all of which occurred secondary to LITT hyperthermia.

\section{Modification of Technique Based On Experience of Adverse Events}

Four of the 62 implanted catheters in this series were positioned suboptimally. To achieve optimal efficacy, placement of the LITT device requires not only accuracy of the target point, but also accuracy of the trajectory so that it is possible to pull back the laser fiber along 1 dimension when multiple treatments along an axis are required. While trajectory planning is required for most stereotactic procedures mostly to avoid vascular structures and CSF spaces, LITT procedures require an additional consideration for treatment.

Of the 62 devices placed, 47 were with the use of a stereotactic frame. Of these 47, 2 had inaccurate catheter placement, giving an overall accuracy of $95.7 \%$ with a framed approach. One instance of device malposition occurred when an alignment rod was not used for a long trajectory. A chi-square analysis demonstrated that observed frequencies of probe misplacement with PAD versus framed technique exceeded expected rates $(p=0.022)$. While initially our patients underwent device placement with the use of the plastic skull anchor supplied by Visualase, we have found better success with metal skull anchors. All 10 catheters placed using these anchors, which are typically used to place stereoelectroencephalography electrodes, had accurate placement. While these differences were not found to be statistically significant ( $\mathrm{p}=$ 0.36 , chi-square test), this is most likely due to the lack of statistical power given the overall low frequency of this adverse event. Notwithstanding, by providing a rigid fixation to the bone, we believe that use of a metal anchor bolt is likely to be the most important factor in achieving ac-

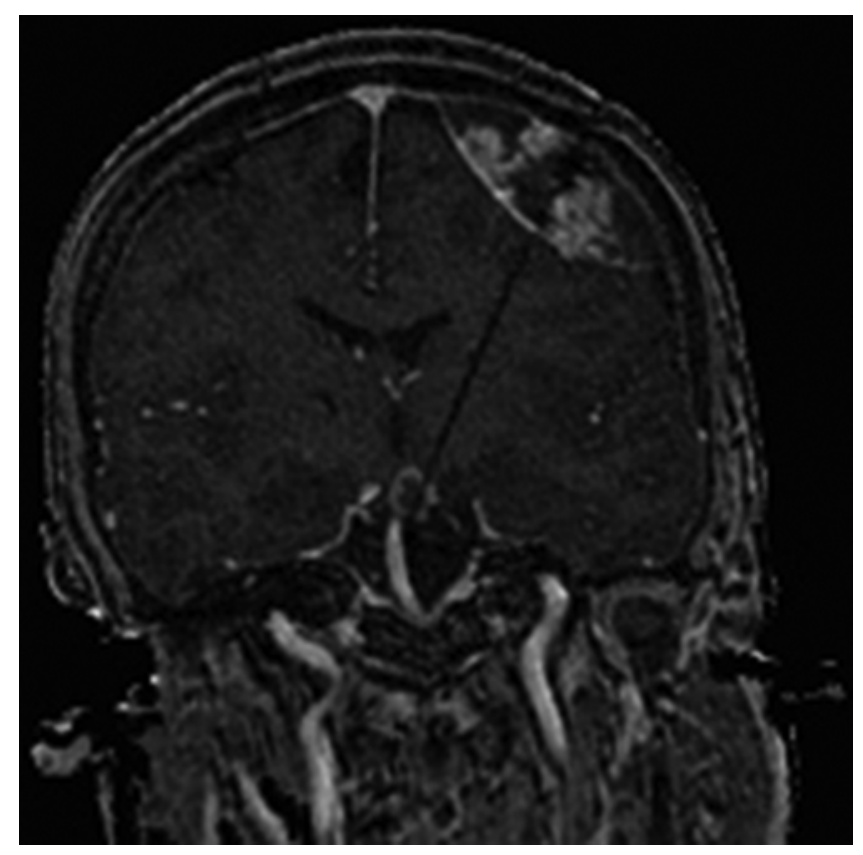

FIG. 2. Case 35. Coronal T1-weighted MR image demonstrating an epidural hematoma at the laser entry site.

curate catheter placement for deep targets. However, as a metal skull anchor may interfere with thermometry, plastic skull anchors may be preferred for treatment of superficial targets (e.g., up to $2 \mathrm{~cm}$ deep to the cortical surface).

Hemorrhage is a known complication of any stereotactic surgery, and has been described previously with LITT. ${ }^{18}$ As a result, for patients needing long trajectories for laser placement, we have adopted a strategy of performing CTA after applying the stereotactic frame and fusing it with a double-dose contrast-enhanced MRI. This allows the trajectory of the laser to be planned in relation to the vasculature, and for the accuracy of the fusion to be assessed with respect to vascular landmarks. While statistical analysis demonstrated no significant difference between expected versus observed rates of hemorrhage with CTA fusion ( $\mathrm{p}=0.48$, chi-square test), we believe that this too is due to low statistical power with an overall low frequency of events. Furthermore, using a small-diameter $(<1 \mathrm{~mm})$ needle to penetrate the dura provides an additional measure to avoid the complication of epidural hemorrhage.

As described above, 3 patients experienced complica-

TABLE 3. Complications in the literature

\begin{tabular}{lccc}
\hline \multirow{2}{*}{ Cause } & \multicolumn{3}{c}{ No. of Patients (\%) } \\
\cline { 2 - 4 } & Total & Transient & Permanent \\
\hline Malposition & $4(1.6)$ & $3(1.2)$ & $1(0.4)$ \\
\hline Catheter passage & $4(1.6)$ & $1(0.4)$ & $3(1.2)$ \\
\hline LITT treatment & $43(17.7)$ & $33(13.6)$ & $10(4.1)$ \\
\hline Technical & $0(0)$ & $0(0)$ & $0(0)$ \\
\hline Total & $51(20.1)$ & $37(15.2)$ & $14(5.6)$ \\
\hline
\end{tabular}


tions directly due to hyperthermia, all of whom harbored CNS tumors and experienced some permanent neurological morbidity. Even with the temperature constraints that can be placed using the Visualase system, caution should be taken when LITT is performed near critical areas when not separated by CSF or vascular structures. The heat sinking properties of CSF and vascular structures are a key feature of LITT that must be considered when planning treatment. To illustrate this point, while the brainstem lies millimeters from targets in the middle temporal lobe, thermal injury to the brainstem has never been reported and it did not occur in any of 21 patients described in this report. This is certainly due to the heat sinks produced by the posterior cerebral artery and suprasellar and ambient cisterns. In an analogous fashion, CSF spaces surround large portions of the corpus callosum, and peduncular hypothalamic hamartomas limit the transmission of hyperthermia. We therefore recommend that maximal energy be kept below $7 \mathrm{~W}$ when treating regions that are not surrounded by heat sinks. Use of a 3-mm diffusing tip also provides a means by which to achieve a more controlled ablation. We applied our initial experience with hyperthermia complications to modify our technique, using the 3-mm diffusing tip when treating patients harboring hypothalamic hamartoma. In doing so, we believe we avoided potential injury to neuroendocrine and limbic structures in the hypothalamic region.

Technical complications occurred in 2 patients, both of which were due to malfunction of the coolant, and one was associated with an intraventricular hemorrhage. In addition to attention to filling of saline coolant, use of metal anchors and deeper anesthesia to reduce head movement may reduce this type of complication.

It was also noted that the rate of complications increased with the number of probes. Either malposition or a complication was experienced $10.8 \%$ of the time when a single probe was passed (4/37 procedures), versus $54.5 \%$ of the time when 2 probes were passed (6/11 procedures), and $100 \%$ of the time when 3 probes were passed $(1 / 1$ procedures). These observed frequencies differed from expected frequencies ( $\mathrm{p}=0.002$, chi-square test) and thus, are not simply additive. Brain shift produced by the placement of one catheter may partly account for this observation. Coolant malfunction is also more likely to occur when multiple catheters are used, as the coolant is required to run through each catheter in series. Therefore, efforts should be made to treat patients with as few laser fibers as possible.

While we have indeed modified our technique based on our experience of the complications described above; any conclusions drawn should be tempered by the fact that the overall complication rate is low and that often certain methods (e.g., frameless stereotaxy) are abandoned with relatively small numbers on the basis of judgments that are based on experience, not statistics. Therefore, it is difficult to make formal recommendations grounded in statistics regarding various aspects of the technique.

\section{Comparison With Other Forms of Minimally Invasive Ablative Therapy}

Advantages of LITT, as opposed to other forms of hy- perthermia treatments and SRS, include the ability to resolve thermometry in near-real time, and to derive (via the Arrhenius model) the estimated "kill zone." ${ }^{-4,10,18,44}$ The effects of treatment may be imaged immediately-another advantage over SRS. While postoperative edema can occur, it tends to be self-limiting, and we did not observe

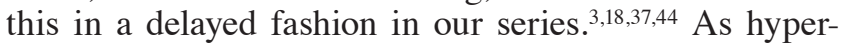
thermia is a nonionizing form of energy deposition, LITT can be safely repeated (as far as anyone knows), unlike the increasing risks of repeating radiation therapy or SRS to the same volume..$^{3,28,39,44}$ Nonetheless, it is hardly surprising that neurological deficits can and do occur when exposing areas of eloquent brain to ablative doses of hyperthermia. High-intensity focused ultrasound (HIFU) has been studied as an ablative method based mainly on hyperthermic effects. ${ }^{8,25}$ HIFU has the added advantage of being noninvasive, requiring (at this point) only the use of a stereotactic frame. However, current technology limits HIFU to treating small volumes within a relatively limited window in the center of the brain. ${ }^{25}$ While future developments may make it a practical tool for patients with a broad range of tumor and functional diagnoses, this is not the case now, nor is this a guaranteed possibility in the future.

Radiofrequency ablation is another approach that has been used as an alternative to traditional open surgery for the treatment of epilepsy since the 1990s. Some series have shown promising results with this technique in middle temporal lobe epilepsy. ${ }^{23,24}$ In addition, radiofrequency ablation has been successfully used for the treatment of hypothalamic hamartomas..$^{20,46}$ However, this technique may only be appropriate for small hypothalamic hamartomas, as a single electrode cannot always successfully ablate a larger lesion, and the seizure-free rate of radiofrequency treatment of larger hypothalamic hamartomas is less than that with a traditional open approach. ${ }^{46}$ The size of a radiofrequency ablation may be limited as each lesion is generally only $5-7 \mathrm{~mm}$ in diameter, ${ }^{14}$ and thus may limit clinical efficacy, as larger volumes are associated with a greater chance of seizure freedom. ${ }^{41}$ In addition, in contrast with LITT, there is no direct monitoring of temperature. Instead, lesioning is measured by an abrupt decrease in the measured current which has been shown to occur with coagulation of brain parenchyma around $75-80^{\circ} \mathrm{C} .{ }^{14}$ One major advantage of LITT over radiofrequency ablation is that the transition zone between ablated and nonablated tissue is on the order of $1 \mathrm{~mm}$ due to the rapid fall off of light energy in biological tissue..$^{17,26}$ This may theoretically reduce the potential for irritated tissue to continue to produce seizures. ${ }^{21}$

The Neuroblate system (Monteris) serves as an alternative to the Visualase system to deliver LITT. Important differences between the 2 systems include the use of $\mathrm{CO}_{2}$ based cooling and the possibility of directed treatment with the Neuroblate systems. Therefore, it is likely to be associated with a different profile of adverse events, especially with regard to accuracy and technical issues. However, the main cautionary lesson, of limiting treatment when CSF spaces do not intervene and caveats involving positioning of anchors and hematoma risk, is likely generalizable regardless of the LITT system that is used. 


\section{Outcomes}

Successful outcome using LITT seizure and tumor con-

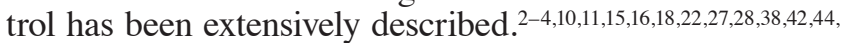
$45,47,48$ Even in our patients who experienced either suboptimal treatment or complication, the majority of patients did well postoperatively. Of the 6 patients with tumors, 4 achieved local control. All 5 epilepsy patients who experienced either complication or suboptimal laser fiber placement have seen some improvement in their seizures. Perhaps the greatest caution raised by our retrospective review involves cases of hyperthermia-induced injury, where complications resulted in neurological deficit.

\section{Conclusions}

The purpose of this study was to discuss the complications we experienced with this technology and evaluate our lessons learned. Accuracy of catheter placement may be optimized by using a stereotactic frame with a metal skull anchor, which should be placed over an alignment rod that passes through both the frame and the bolt. To reduce the risk of hemorrhage, CTA with MRI fusion can be used to avoid vascular injury, and a narrow gauge needle should be used to penetrate the dura. To minimize neurological deficits, smaller diffusing tips should be used, and hyperthermia doses should be modified for ablation targets that lie close to critical neural structures (e.g., brainstem, spinal cord, and near eloquent cortex) without intervening fluid spaces. Finally, the saline coolant flow must remain continuous, and the cooling catheter is vulnerable to damage when it exits the skull posteriorly and the patient is not sedated.

LITT is a promising new tool for the treatment of patients with brain tumors and epilepsy. As is the case when adopting any new technology, a careful and honest evaluation of suboptimal circumstances will result in refinement of technique and improved clinical outcomes.

\section{References}

1. Bown SG: Phototherapy in tumors. World J Surg 7:700-709, 1983

2. Carpentier A, Chauvet D, Reina V, Beccaria K, Leclerq $\mathrm{D}, \mathrm{McNichols} \mathrm{RJ}$, et al: MR-guided laser-induced thermal therapy (LITT) for recurrent glioblastomas. Lasers Surg Med 44:361-368, 2012

3. Carpentier A, McNichols RJ, Stafford RJ, Guichard JP, Reizine D, Delaloge S, et al: Laser thermal therapy: realtime MRI-guided and computer-controlled procedures for metastatic brain tumors. Lasers Surg Med 43:943-950, 2011

4. Carpentier A, McNichols RJ, Stafford RJ, Itzcovitz J, Guichard JP, Reizine D, et al: Real-time magnetic resonanceguided laser thermal therapy for focal metastatic brain tumors. Neurosurgery 63 (1 Suppl 1):ONS21-ONS29, 2008

5. Chao ST, Ahluwalia MS, Barnett GH, Stevens GH, Murphy ES, Stockham AL, et al: Challenges with the diagnosis and treatment of cerebral radiation necrosis. Int J Radiat Oncol Biol Phys 87:449-457, 2013

6. Choudhri O, Karamchandani J, Gooderham P, Steinberg GK: Flexible omnidirectional carbon dioxide laser as an effective tool for resection of brainstem, supratentorial, and intramedullary cavernous malformations. Neurosurgery 10 (Suppl 1):34-45, 2014

7. Choudhri O, Lober RM, Camara-Quintana J, Yeom KW,
Guzman R, Edwards MS: Carbon dioxide laser for corpus callosotomy in the pediatric population. J Neurosurg Pediatr 15:321-327, 2015

8. Chu KF, Dupuy DE: Thermal ablation of tumours: biological mechanisms and advances in therapy. Nat Rev Cancer 14:199-208, 2014

9. Consiglieri GD, Killory BD, Germain RS, Spetzler RF: Utility of the $\mathrm{CO}_{2}$ laser in the microsurgical resection of cavernous malformations. World Neurosurg 79:714-718, 2013

10. Curry DJ, Gowda A, McNichols RJ, Wilfong AA: MRguided stereotactic laser ablation of epileptogenic foci in children. Epilepsy Behav 24:408-414, 2012

11. Esquenazi Y, Kalamangalam GP, Slater JD, Knowlton RC, Friedman E, Morris SA, et al: Stereotactic laser ablation of epileptogenic periventricular nodular heterotopia. Epilepsy Res 108:547-554, 2014

12. Fabiano AJ, Alberico RA: Laser-interstitial thermal therapy for refractory cerebral edema from post-radiosurgery metastasis. World Neurosurg 81:652.e1-652.e4, 2014

13. Falowski S, Byrne R: Corpus callosotomy with the $\mathrm{CO}_{2}$ laser suction device: a technical note. Stereotact Funct Neurosurg 90:137-140, 2012

14. Guénot M, Isnard J, Ryvlin P, Fischer C, Mauguière F, Sindou M: SEEG-guided RF thermocoagulation of epileptic foci: feasibility, safety, and preliminary results. Epilepsia 45:1368-1374, 2004

15. Hawasli AH, Bagade S, Shimony JS, Miller-Thomas M, Leuthardt EC: Magnetic resonance imaging-guided focused laser interstitial thermal therapy for intracranial lesions: single-institution series. Neurosurgery 73:1007-1017, 2013

16. Hawasli AH, Kim AH, Dunn GP, Tran DD, Leuthardt EC: Stereotactic laser ablation of high-grade gliomas. Neurosurg Focus 37(6):E1, 2014

17. Heisterkamp J, van Hillegersberg R, Zondervan PE, IJzermans JN: Metabolic activity and DNA integrity in human hepatic metastases after interstitial laser coagulation (ILC). Lasers Surg Med 28:80-86, 2001

18. Jethwa PR, Barrese JC, Gowda A, Shetty A, Danish SF: Magnetic resonance thermometry-guided laser-induced thermal therapy for intracranial neoplasms: initial experience. Neurosurgery 71 (1 Suppl Operative):133-145, 2012

19. Kahn T, Bettag M, Ulrich F, Schwarzmaier HJ, Schober R, Fürst G, et al: MRI-guided laser-induced interstitial thermotherapy of cerebral neoplasms. J Comput Assist Tomogr 18:519-532, 1994

20. Kameyama S, Murakami H, Masuda H, Sugiyama I: Minimally invasive magnetic resonance imaging-guided stereotactic radiofrequency thermocoagulation for epileptogenic hypothalamic hamartomas. Neurosurgery 65:438-449, 2009

21. Lee Titsworth W, Murad GJ, Hoh BL, Rahman M: Fighting fire with fire: the revival of thermotherapy for gliomas. Anticancer Res 34:565-574, 2014

22. Leonardi MA, Lumenta CB: Stereotactic guided laserinduced interstitial thermotherapy (SLITT) in gliomas with intraoperative morphologic monitoring in an open MR: clinical experience. Minim Invasive Neurosurg 45:201-207, 2002

23. Liscak R, Malikova H, Kalina M, Vojtech Z, Prochazka $\mathrm{T}$, Marusic P, et al: Stereotactic radiofrequency amygdalohippocampectomy in the treatment of mesial temporal lobe epilepsy. Acta Neurochir (Wien) 152:12911298,2010

24. Malikova H, Kramska L, Vojtech Z, Lukavsky J, Liscak R: Stereotactic radiofrequency amygdalohippocampectomy: two years of good neuropsychological outcomes. Epilepsy Res 106:423-432, 2013 
25. McDannold N, Clement GT, Black P, Jolesz F, Hynynen K: Transcranial magnetic resonance imaging-guided focused ultrasound surgery of brain tumors: initial findings in 3 patients. Neurosurgery 66:323-332, 2010

26. McNichols RJ, Gowda A, Kangasniemi M, Bankson JA, Price RE, Hazle JD: MR thermometry-based feedback control of laser interstitial thermal therapy at $980 \mathrm{~nm}$. Lasers Surg Med 34:48-55, 2004

27. Mohammadi AM, Hawasli AH, Rodriguez A, Schroeder JL, Laxton AW, Elson P, et al: The role of laser interstitial thermal therapy in enhancing progression-free survival of difficult-to-access high-grade gliomas: a multicenter study. Cancer Med 3:971-979, 2014

28. Norred SE, Johnson JA: Magnetic resonance-guided laser induced thermal therapy for glioblastoma multiforme: a review. BioMed Res Int 2014:761312, 2014

29. Quigg M, Harden C: Minimally invasive techniques for epilepsy surgery: stereotactic radiosurgery and other technologies. J Neurosurg 121 (Suppl):232-240, 2014

30. Rahmathulla G, Marko NF, Weil RJ: Cerebral radiation necrosis: a review of the pathobiology, diagnosis and management considerations. J Clin Neurosci 20:485-502, 2013

31. Rahmathulla G, Recinos PF, Kamian K, Mohammadi AM, Ahluwalia MS, Barnett GH: MRI-guided laser interstitial thermal therapy in neuro-oncology: a review of its current clinical applications. Oncology 87:67-82, 2014

32. Rahmathulla G, Recinos PF, Valerio JE, Chao S, Barnett GH: Laser interstitial thermal therapy for focal cerebral radiation necrosis: a case report and literature review. Stereotact Funct Neurosurg 90:192-200, 2012

33. Reimer P, Bremer C, Horch C, Morgenroth C, Allkemper T, Schuierer G: MR-monitored LITT as a palliative concept in patients with high grade gliomas: preliminary clinical experience. J Magn Reson Imaging 8:240-244, 1998

34. Roux FX, Merienne L, Leriche B, Lucerna S, Turak B, Devaux B, et al: Laser interstitial thermotherapy in stereotactical neurosurgery. Lasers Med Sci 7:121-126, 1992

35. Sakai T, Fujishima I, Sugiyama K, Ryu H, Uemura K: Interstitial laserthermia in neurosurgery. J Clin Laser Med Surg 10:37-40, 1992

36. Schulze PC, Vitzthum HE, Goldammer A, Schneider JP, Schober R: Laser-induced thermotherapy of neoplastic lesions in the brain-underlying tissue alterations, MRImonitoring and clinical applicability. Acta Neurochir (Wien) 146:803-812, 2004

37. Schwabe B, Kahn T, Harth T, Ulrich F, Schwarzmaier HJ: Laser-induced thermal lesions in the human brain: short- and long-term appearance on MRI. J Comput Assist Tomogr 21:818-825, 1997

38. Schwarzmaier HJ, Eickmeyer F, von Tempelhoff W, Fiedler VU, Niehoff H, Ulrich SD, et al: MR-guided laser-induced interstitial thermotherapy of recurrent glioblastoma multiforme: preliminary results in 16 patients. Eur J Radiol 59:208-215, 2006

39. Schwarzmaier HJ, Eickmeyer F, von Tempelhoff W, Fiedler VU, Niehoff H, Ulrich SD, et al: MR-guided laser irradiation of recurrent glioblastomas. J Magn Reson Imaging 22:799 803,2005

40. Schwarzmaier HJ, Yaroslavsky IV, Yaroslavsky AN, Fiedler V, Ulrich F, Kahn T: Treatment planning for MRI-guided laser-induced interstitial thermotherapy of brain tumors-the role of blood perfusion. J Magn Reson Imaging 8:121-127, 1998

41. Shamim S, Wiggs E, Heiss J, Sato S, Liew C, Solomon $\mathrm{J}$, et al: Temporal lobectomy: resection volume, neuropsychological effects, and seizure outcome. Epilepsy Behav 16:311-314, 2009

42. Sloan AE, Ahluwalia MS, Valerio-Pascua J, Manjila S, Torchia MG, Jones SE, et al: Results of the NeuroBlate System first-in-humans Phase I clinical trial for recurrent glioblastoma: clinical article. J Neurosurg 118:1202-1219, 2013

43. Sugiyama K, Sakai T, Fujishima I, Ryu H, Uemura K, Yokoyama T: Stereotactic interstitial laser-hyperthermia using Nd-YAG laser. Stereotact Funct Neurosurg 5455:501-505, 1990

44. Torres-Reveron J, Tomasiewicz HC, Shetty A, Amankulor NM, Chiang VL: Stereotactic laser induced thermotherapy (LITT): a novel treatment for brain lesions regrowing after radiosurgery. J Neurooncol 113:495-503, 2013

45. Tovar-Spinoza Z, Carter D, Ferrone D, Eksioglu Y, Huckins S: The use of MRI-guided laser-induced thermal ablation for epilepsy. Childs Nerv Syst 29:2089-2094, 2013

46. Wang W, Wang W, Guo X, Zeng Y, Jiang X: Hypothalamic hamartoma causing gelastic seizures treated with stereotactic radiofrequency thermocoagulation. Epileptic Disord 11:333-338, 2009

47. Wilfong AA, Curry DJ: Hypothalamic hamartomas: optimal approach to clinical evaluation and diagnosis. Epilepsia 54 (Suppl 9):109-114, 2013

48. Willie JT, Laxpati NG, Drane DL, Gowda A, Appin C, Hao $\mathrm{C}$, et al: Real-time magnetic resonance-guided stereotactic laser amygdalohippocampotomy for mesial temporal lobe epilepsy. Neurosurgery 74:569-585, 2014

\section{Disclosures}

The authors report no conflict of interest concerning the materials or methods used in this study or the findings specified in this paper.

\section{Author Contributions}

Conception and design: Mehta, Schulder. Acquisition of data: Mehta, Pruitt, Gamble, Schulder. Analysis and interpretation of data: Mehta, Pruitt, Gamble. Drafting the article: Mehta, Pruitt, Schulder. Critically revising the article: Schulder. Reviewed submitted version of manuscript: all authors. Approved the final version of the manuscript on behalf of all authors: Mehta. Statistical analysis: Mehta, Pruitt. Study supervision: Mehta.

\section{Supplemental Information}

\section{Previous Presentations}

Portions of this work were presented at the AANS 83rd Annual Scientific Meeting on May 6, 2015, in Washington, DC.

\section{Correspondence}

Ashesh D. Mehta, Department of Neurosurgery, North Shore University Hospital, 300 Community Dr., Manhasset, NY 11549. email: amehta@northwell.edu. 